\title{
Traim tasol ... Cultural heritage management in Papua New Guinea
}

\author{
Tim Denham, La Trobe University, Melbourne, Australia
}

In this chapter, I discuss a range of issues associated with cultural heritage management practice in Papua New Guinea today. I build my discussion around three different types of cultural resource management project that I have undertaken. These increase in complexity, scale and scope. First, I describe a community heritage project among the Kalam of the Simbai Valley, Madang Province. Second, I raise several issues associated with the World Heritage nomination of the Kuk Early Agricultural Site. Third, I make some generalised observations on the expanding commercial cultural heritage management sector. The first two sections are highly specific, whereas the third section is more polemical. Each gives a flavour of the variety of my experiences, reflects the range of practices occurring within the country today, and is intended to be illustrative rather than comprehensive.

I have undertaken fieldwork in Papua New Guinea over a period of 20 years (1990-2010). My first two-month field visit in 1990 among the Kalam at Tsendiap and Tsarep in the Lower Jimi Valley, Western Highlands Province was incidental to a thesis on cultural geography (Denham 1996). Since then, my professional interests in Papua New Guinea have been either academicallyoriented archaeological research or cultural heritage management. Archaeological research has focussed on traditional forms of plant use, including early agriculture, in the highland interior during the Holocene (Denham et al. 2003). Over the last six years my focus has broadened to include the history of occupation generally, as well as a range of different cultural heritage management projects within the country.

\section{A community project among the Kalam}

A community-based ethnoarchaeological field project was initiated among the Kalam in the Simbai Valley of Madang Province in 2007 (Bedingfield and Denham 2008). The project arose out of discussions between Dr Ian Saem Majnep and myself, and was deliberately focussed on the Simbai Valley, as opposed to the Upper Kaironk Valley. The latter had already been subject to considerable multi-disciplinary research (e.g. Bulmer 1977; Majnep and Bulmer 1977, 2007). Sadly, Dr Majnep died shortly before our fieldwork began in 2007, although we were able to pay our respects to his family and matmat (burial ground) at Waiak in the Upper Kaironk Valley.

The intention of the research was to link archaeological investigations of rockshelters and open sites to the well-documented oral traditions and ethnoscience of Kalam communities (see Bulmer 1991 for a list of relevant references). Mr Kari Heri, a field officer at the Papua New Guinea Museum and Art Gallery (hereafter 'PNG National Museum'), accompanied the team during 
both field seasons. Unfortunately, the research project was suspended during the second field season in 2008, which was the first season of excavation, due to an accident (Bedingfield 2009). For various reasons, the project has not yet been restarted.

While at Simbai in 2007 we stayed at the Kalam Guest House at Nukunt, adjacent to the Kalam Cultural Museum. The Kalam Cultural Museum is a community initiative designed to foster a sense of cultural awareness among community members at Simbai and was part of initiatives to generate tourism in the area, such as the Kalam Culture Festival. The Museum housed a collection of ancient and recent items of cultural interest. Archaeological artefacts donated by community members included stone club heads, stone mortars and pestles, stone bowls, stone files, stone axeadzes and bone points. These items had been collected adventitiously by community members while gardening, building houses, digging ditches and so on, or had been kept in homesteads or men's houses in the past. Other donated items of recent material culture included spears, bilas ('body decorations'), headdresses, various types of animal trap (some of which functioned) and tapa ('bark cloth') beaters.

We were requested by the museum curators, Ernest Simgi and Ishmael Yei, to inventory all items of any antiquity. The reasons were threefold: to assist the curators with an inventory, to provide visitors with information, and for safekeeping. Following discussions with community members it became clear that local people had become increasingly worried that items housed in the Museum might be stolen and sold.

We designed and filled a recording sheet with simple descriptions and diagnostic photographs for each artefact (Kalam Cultural Museum et al. 2008). We were aided by Dr Pam Swadling (formerly Head of Archaeology, PNG National Museum) who assisted with the classification and description of stone mortars, pestles and bowls. The subsequent inventory was lodged with local and national authorities at the Kalam Cultural Museum and at the PNG National Museum, respectively. Copies are also retained by authors in Australia. The illustrated artefact inventory will ensure that if any artefacts are stolen and are attempted to be sold on the international antiquities market, that they can be identified and returned to their rightful owners.

The recording of artefacts at the Kalam Cultural Museum indicates how field teams can meaningfully contribute to community-initiated cultural heritage management projects while undertaking their own research. This work can be undertaken incidentally while in the field and represents a small reciprocation on the part of the field team with their hosts (see Muke 2000). Similar types of local community initiative seem to be becoming more common across Papua New Guinea today. These initiatives are sometimes designed to attract tourists, but more often they are a means for communities to re-identify, teach and safeguard their own material culture for future generations.

\section{Nominating the Kuk Early Agricultural Site}

The archaeological site at Kuk bears witness to multiple phases of wetland manipulation and drainage for cultivation extending from at least 7000-6400 years ago to the present, and potentially to 10,000 years ago (Golson 1977; Denham et al. 2003, 2004; Bayliss-Smith 2007). As such, it is important globally for understanding the emergence of agriculture and its contribution to the transformation of human society during the Holocene. As well as its significance to the academic community, the agricultural history of Papua New Guinea is taught in schools across the country, is a source of national pride, and is a potential focus of national identity (cf. Mangi 1994). As such, Kuk is an excellent example of knowledge transfer. 
Papua New Guinea became a State Party to the World Heritage Convention in 1997. Since that date, the country has worked towards the establishment of a World Heritage site. The first tentative steps for the nomination of Kuk had already begun by 1997 (Golson and Swadling 1998), the year I began my PhD research on the site (Denham 2003), and continued in various forms for the next ten years (Muke et al. 2007).

In 2006, John Muke and I were invited to participate in the National World Heritage Action Planning Workshop in Port Moresby. At this workshop, a Tentative List of intended World Heritage sites for the country was formulated, an institutional framework and strategy were developed for the nomination and management of World Heritage sites within the country, and steps were taken to ensure the completion of the nomination of the Kuk Early Agricultural Site. At the workshop, we were then asked by the Department of Environment and Conservation, which is responsible for World Heritage in the country, to complete the nomination process. Together with the assistance of various collaborators and contributions, we were able to submit the nomination in early 2007 (DEC 2007; Muke et al. 2007). In 2008, the Kuk Early Agricultural Site was formally accepted onto UNESCO's World Heritage List at the $32^{\text {nd }}$ Session of The World Heritage Committee in Québec City, Canada. I was fortunate enough to be present at that meeting as the sole representative for Papua New Guinea's nomination.

Kuk started as an archaeological site, but it has become Papua New Guinea’s first and only World Heritage site. The tortuous history of the Kuk nomination process up until 2007 is the subject of several publications (Ketan 1998; Strathern and Stewart 1998; Denham 1999; Ketan and Muke 2001; Muke et al. 2007). It will not be recounted in detail here. The complexity of the nomination process is instructive and a few key aspects are summarised.

First, existing legislation can be used to manage World Heritage sites within the country; namely, there is no need to formulate and enact new legislation to manage World Heritage. For Kuk, enabling legislation includes the National Cultural Property (Preservation) Act and associated Regulations (1965) (considered below) and the Organic Law on Provincial and Local Level Governments (1995/1997). The latter empowers local communities to generate laws that are nationally binding to protect their own cultural and natural resources. The intention is to get the landholders at Kuk to voluntarily create an Organic Law based upon the traditional land use management plan for the site.

Second, the Kuk nomination was successful despite an ongoing land ownership dispute. This is unusual in a global context because ordinarily land disputes undermine successful cultural heritage management projects. In June 1968, the Kawelka landowners sold the land at Kuk to the Australian Colonial Administration of the Territory of Papua New Guinea (Ketan 1998:18; Muke 1998:20-21). Kuk formed part of the endowment of government land inherited by Papua New Guinea at Independence in 1975. The land was used to establish a tea research station, which subsequently became an agricultural research station. In common with many other rural institutions, the research station was mothballed in 1990 and was gradually reoccupied by traditional Kawelka owners during the 1990s (Muke 1998). At the time of nomination in 1997, legal ownership rested with the national government (i.e. Kuk was alienated land) yet traditional ownership and use rights had been reasserted by the Kawelka. Having sold the land, the Kawelka saw it empty and re-occupied it, thereby effectively becoming squatters on their own traditional land. The draft management plan needed to reconcile both claims to ownership: the State's (legal) and the Kawelka's (traditional). At the same time, any solution needed to avoid setting an awkward legal precedent that could potentially legitimate the re-occupation of alienated land elsewhere in the country. The draft management plan effectively formalises and legitimises the status quo: the 
Kawelka acknowledge the government's legal claim, and the government acknowledges the rights of the Kawelka to occupy and use the land in traditional ways that accord with management guidelines.

Third and following, the traditional land use management plan for Kuk links the distant past to current cultivation practices. The ongoing management of Kuk effectively requires continued occupation and cultivation by Kawelka because they provide a connection between archaeological and contemporary practices through which the site gets it significance as an organically-evolved cultural landscape. Indeed, from this perspective, ongoing cultivation is not to be viewed negatively, rather it adds layers of meaning and significance to the site.

Fourth, the proposed long-term management plan for Kuk was designed to be sustainable within the unpredictable fiscal and political environments of modern-day Papua New Guinea. The longterm management of the site would not be feasible if it relied upon large annual budgets and political stability. The draft management plan was based around low annual inputs of money and was adapted to operate in an environment of recurrent political instability. The management plan, as originally envisaged, incorporated a culturally appropriate sense of reciprocity: provincial authorities were to provide or upgrade existing services, e.g. road grading and clean water, while Kawelka were to accede to management guidelines in terms of prohibited activities, e.g. deep drainage or digging, planting of trees and mechanised cultivation. More grandiose schemes that proposed a visitor's centre and guesthouse may not be sustainable within the current social and economic climate of Western Highlands Province; there is an insufficient number of tourists to make such enterprises self-sustaining.

Since the successful nomination of the site in 2008, there have been some advances within Papua New Guinea in terms of the management of Kuk and World Heritage generally (Denham 2012). For Kuk these advances include the development of provincial and national committees regulating World Heritage, the development of educational materials, dissemination of literature for the general public inside and outside the country (Denham 2008a and 2008b, respectively), and advances in the preparation of a traditional land use management plan. As with many things, however, continued progress in the management of Kuk ebbs and flows; it needs ongoing commitments at the local, provincial and national levels. Foremost it requires constant communication and engagement with Kawelka landholders at Kuk.

\section{The commercial sector}

Swadling (1983 in Mandui 2006:380) noted almost thirty years ago, that most forms of modern development in Papua New Guinea erode the 'unwritten' record of the past. Over the last seven years, I have been involved with several contract, or commercial, cultural heritage management projects within Papua New Guinea. Cultural heritage management is undertaken as part of the Environmental Impact Assessment (EIA) process, and most of the larger projects are associated with mining and petroleum exploitation. Cultural heritage forms part of the complex social, economic and environmental impacts of resource extraction projects (Filer and Macintyre 2006; Bainton 2010). Resource exploitation projects offer challenges and opportunities for cultural heritage management within Papua New Guinea (Bainton et al. 2011). These projects are usually subject to complex confidentiality and intellectual property agreements, which can make reference to specific aspects of an individual development problematic.

Academic archaeologists occasionally work on commercial projects in Papua New Guinea, and elsewhere, in order to gain access to sites for research purposes. Archaeological and cultural heritage consultancies now dwarf in terms of value and volume research projects in these fields 
within the country. The financial and logistical support offered by commercial projects far exceeds that which can be mobilised on research grants, and significant academic contributions can derive from such involvement (e.g. McNiven et al. 2011; Spriggs 2012).

The discussion consists of general observations on the practice of cultural heritage management (CHM) within the commercial sector in Papua New Guinea. It is based on my own experiences. This presentation is necessarily general in order to de-identify any individual agency, group or company. Consequently, it is possible to raise several thorny issues, comprising:

1. the respective roles of national and overseas contractors;

2. the role and functioning of the regulatory authority; and,

3. where to now?

These comments are primarily directed towards people outside the country, rather than to those within Papua New Guinea.

\section{The respective roles of national and overseas consultants}

Consultant practitioners within the commercial CHM sector are largely either national Papua New Guineans or people based in Australia. National practitioners can be characterised as mostly belonging to two ill-defined groups: those who have worked within archaeology or forms of cultural heritage within the country for many years, even decades; and, those who are newly trained in modern archaeological field methods. The former group includes long-term advocates of cultural heritage practice within the country, even though some have not had regular employment. Some of this group were trained in archaeological field methods decades ago and institutional support for this group over the last few decades has been highly variable. The latter group are younger and relatively inexperienced; although many have benefitted from closer associations with recent cultural resource management and research projects. Additionally, there are people employed in the industry who have received no formal training in archaeology or cultural heritage; their skills and competence vary greatly. Members of any group may work on projects ultimately run by consultant companies owned by Papua New Guineans or overseas.

In recent years, some of the older national practitioners have found it difficult to find regular or permanent work. There are many reasons for this, but it reflects a tension. On the one hand it makes sense to educate a new generation of archaeologists and cultural heritage practitioners in the latest techniques; this is common practice in any country, especially when the industry is rapidly expanding. On the other hand, care needs to be taken to accommodate and include professionals who have often struggled in adverse conditions for decades, and who may in part have helped generate the current cultural heritage management climate within the country.

Most cultural heritage management projects I have been involved with require participation by national practitioners. Some far-sighted resource development companies also require Indigenous training and capacity building to be incorporated into long-term project goals. The lead-in time and planned operating time of many resource sector developments are measured in decades rather than years. Consequently, there is enormous scope for the training of local people, namely individuals selected from the communities impacted by the development, to be educated (at national high school and at university) by the resource company and trained in cultural heritage management. Thereby, members of communities can be trained and employed to manage their own cultural heritage, mediate between community and company, and liaise with provincial and national authorities. 
It is fair to say that most overseas contractors and practitioners in cultural resource management had no or limited previous experience working in Papua New Guinea or any other developing nation. At one level, this should not be a problem, as experience and skills are transferable. However, there are some issues that need addressing.

I have heard it said that undertaking cultural heritage management among local communities in Papua New Guinea is the same as working among Aboriginal groups in Australia. Although the techniques of archaeological and cultural heritage practice may be comparable, such statements show an ignorance of the cultural, historical and social contexts within which the work takes place. The history of local communities in Papua New Guinea is different to that among Aboriginal groups in Australia. Their respective histories of colonialism (namely, the relationship between local communities and agents of European/Australian colonial rule) and internal colonialism (namely, the relationship between communities and national entities following formation of independent nation states) are different. Significantly, communities in Papua New Guinea have, for the most part, not been alienated from their land and maintain a degree of sovereignty over the land and its use. Consequently, many groups in Papua New Guinea had maintained a range of traditional cultural practices and their language until relatively recently. Although there may be points of similarity, there are clear differences between Australia and Papua New Guinea, most pertinently relating to culture, archaeology and heritage, as well as to regulatory environment. Ideally, overseas consultants working in the commercial sector in Papua New Guinea should undergo some form of rigorous cultural awareness training before arriving in-country. Such training will hopefully avoid the neo-colonial tendencies that creep into some expatriate practice.

In 2006, Herman Mandui (2006:381) asked "Who will take responsibility for management of Papua New Guinea's cultural heritage?” Ultimately, Papua New Guineans need to be enabled to take full responsibility for the management of their own cultural resources. Through many ongoing initiatives, such as multi-institutional collaboration (e.g. McNiven et al. 2011), it is hoped that the current reliance on overseas consultants - especially at managerial and supervisory levels - will give way to an increasing reliance on national practitioners over the next decade. However, such a transition has been a recurrent theme in the recent history of cultural heritage management within the country (Craig 1996).

\section{Role and functioning of the regulatory authority}

The Papua New Guinea National Museum and Art Gallery (PNG National Museum) is the regulator of archaeological research and most cultural heritage management (World Heritage issues being a notable exception) within the country. The PNG National Museum issues permits to undertake archaeological and cultural heritage fieldwork, as well as to export materials for analysis; monitors ongoing projects, often through the presence of a field officer; and, maintains the material and report archives for projects conducted within the country.

The National Museum and Art Gallery Act 1992 made the PNG National Museum responsible for preservation of cultural heritage, including the management, documentation and preservation of archaeological sites and relics within the country. The Act states that the Museum is to 'maintain the national register of traditional and archaeological sites, locate and record prehistoric sites and monuments, and carry out the salvage of archaeological excavations as required by the National Cultural Property (Preservation) Act 1965 and the Environmental Planning Act 1978' (i.e. the National File of Traditional and Prehistoric Sites).

The management of cultural property is vested in the Trustees of the Papua New Guinea National Museum and Art Gallery, under the National Cultural Property (Preservation) Act 1965, which is the primary legislation relevant to immovable cultural resources, namely archaeological and 
cultural sites. Provisions of the Act pertain to 'any property, movable or immovable, of particular importance to the cultural heritage of the country', including 'any object, natural or artificial, used for, or made or adapted for use for, any purpose connected with the traditional cultural life of any of the peoples of the country, past or present'. Other relevant legislation includes the Conservation Areas Act 1978 and the Cemeteries Act 1955. The Environmental Planning Act 1978 was repealed and superseded by the Environment Act 2000, which unlike its predecessor makes no reference to cultural aspects of human communities.

Against an often challenging operational backdrop, the PNG National Museum is required to regulate multiple, multi-phased cultural heritage management projects, as well as all archaeological research within the country. Some projects are massive by any international standard, running into many millions of Australian dollars, and occur in remote regions spread across the country. Yet, there seems to be a major and disproportionate mismatch between the funding allocated to cultural heritage management projects within Papua New Guinea today, and the resources allocated to the regulation of these activities. Not only is the Archaeology Section at the PNG National Museum under-resourced for such a task, its highly committed staff have not been trained to work in this type of regulatory environment. Until about ten years ago, a greater part of their role was to regulate archaeological research within the country; cultural heritage management was much more limited in scope (Mandui 2006; exceptions include Swadling 1973).

\section{Where to now?}

Given the apparent problems and tensions within current cultural heritage management practice in Papua New Guinea, what should happen next? Well, there is no carte blanche. It would seem appropriate to develop a strategy that builds upon the range of expertise within the country today, using current professionals, institutions and legislative environment. In this regard, it is necessary to marry short-term goals with long-term change.

First, although a new professional cohort is being trained, this does not mean that those national practitioners who have struggled against the odds and without a regular position or income for decades should be overlooked. These are the Indigenous, national leaders within the field that the next generation will look to for guidance. Their voices and experiences can provide the essential, culturally appropriate insights on how to improve current practice.

Second, there is no easy fix for institutional capacity and regulatory frameworks within Papua New Guinea. Existing institutional structures and practices are set to continue for the foreseeable future. A short-term improvement in the regulation of cultural heritage activities could be assisted, especially drawing on external expertise and resources, through:

1. inter-governmental assistance, both within and outside of country, in the training of staff in cultural heritage regulation. Ideally, this would involve placement within regulatory institutions in other independent Pacific Island nations;

2. revision of standard procedures for the monitoring and reviewing of cultural heritage management projects, including provision for feedback and follow-up to local communities (Mangi 1994), and the training of staff in these procedures;

3. adequate resourcing, including the development of a GIS-based inventory of the National Register, together with training of staff in the maintenance and use of the system; and

4. increased staffing of the Archaeology Section at the PNG National Museum to include a Head, sufficient field officers, National Register officer (GIS/paper archive) and material archive/collections officer.

Cultural heritage legislation within Papua New Guinea is in urgent need of revision. Any legislative reform needs to take into account foreseeable institutional arrangements, any proposed reforms to land ownership laws, as well as practical matters, such as enforcement mechanisms. Legislation needs to be culturally and institutionally appropriate. For example, it would not be appropriate 
to import or adapt legislation from Australian states with robust and well-resourced regulatory authorities; the institutional context is very different in Papua New Guinea. Any legislation needs to balance the respective rights of individual communities to look after and curate their own heritage, while simultaneously acknowledging the collective right to look after and curate significant heritage at the national level. The sought-for balance between communities and national institutions reflects a unique balance within contemporary Papua New Guinea society.

Third, if codes of practices are developed to regulate archaeological fieldwork and cultural heritage management, it would seem that these need to be appropriate, relevant and sustainable within the Papua New Guinean context. It is not acceptable to have cultural management projects undertaken by untrained practitioners. However, it would be equally inappropriate to advocate codes of practice that are more stringent than those that occur in almost any developed nation. Although well-meaning in trying to raise standards, any such move would almost certainly be counter-productive and unsustainable.

Codes of practice need to be relevant to the regulatory/legislative framework within the country, as well as to cultural, professional and socio-economic contexts. By way of an analogy, have we learnt from debates in economic development over the last 50 years? Advocates of neo-liberal development and modernisation were well-intentioned; they sought to fast-track the economic development and social transformation of 'undeveloped nations' (Chisholm 1982). New technology and new methods were imported from developed nations and superseded traditional practices, often with disastrous consequences (Hettne 1990). Following several waves of critique, it became apparent that development needed to be appropriate to any given context in order to be sustainable (Richards 1985). Similarly, any codes of practice for cultural heritage management need to be appropriate to the modern socio-economic climate and cultures of Papua New Guinea in order to be relevant and sustainable.

Sequential commentators have lamented the perception that cultural heritage management is considered an impediment to economic development in Papua New Guinea (Muke 1998; Mandui 2006), as is often the case elsewhere. Why is this the case? Rather than apportioning blame solely outwards, onto others, should we not take some collective responsibility? Has not a failure of professional leadership, especially in communication to the general public and other spheres of society, also contributed to this perception?

There is great scope for improving commercial cultural heritage management practices within Papua New Guinea. Any such moves will require broad consultation with those voices, national or otherwise, who have experience working in cultural heritage within Papua New Guinea over the long-term. Additional consultation is needed with a wide range of stakeholder groups, including the PNG National Museum, National Cultural Commission, Department of Environment and Conservation and National Research Institute - as well as government agencies and nongovernmental organisations associated with resource exploitation and potential land reform. Without an inclusive process, well-intended recommendations are likely to founder.

\section{Turning a corner ...}

Three different types of cultural heritage management are described above in order to provide an impression of the range of practices occurring across Papua New Guinea at the time of writing. I did not dwell on the specifics of practice, such as field survey, site recording and excavation techniques, these are the subject of field manuals. Similarly, I have not sought to situate cultural heritage management within Papua New Guinea into broader global debates within the field. My observations and discussions are drawn from personal experience and are designed to highlight some of the outstanding issues as I see them at this moment in time. 
All cultural heritage within Papua New Guinea belongs to a community. Irrespective of whether the sites or finds connect with current Indigenous knowledge about the past or belong to realms of the past unconnected with contemporary knowledge and practices. All finds and sites are connected to the land (including water-bodies) in some way, and all land has traditional owners. At the same time, these communities, their land and cultural heritage belong to a nation. The balance between local and national interests is not always clear within many spheres of Papua New Guinean society, and future developments across the spectrum of cultural heritage management will need to take into account this dynamic tension.

Another dynamic tension exists in the balance between overseas and national practitioners in all spheres of cultural heritage management, and particularly in the commercial sector. Over the next decade, it is to be hoped that the number of overseas consultants working within the country will diminish; their roles will increasingly be taken up by national practitioners at all professional levels. At the same time, it is hoped that the regulatory environment for cultural heritage within the country will undergo review and that a system tailored and appropriate for the Papua New Guinean context emerges. During this period, the primary role for those based overseas will be to enable this transition in various ways, namely, through mentoring, education and training, provision of equipment and infrastructure, and so on. Care needs to be taken that we do indeed enable change, rather than direct change to conform to frameworks of practice with which we are familiar, namely, those in Australia.

\section{Acknowledgements}

I would like to thank the editors of this volume for inviting me to contribute. I would also like to thank several individuals and two reviewers, who all wish to remain anonymous, for comments on drafts of this paper. Their contributions are greatly appreciated. This article was originally written in 2011.

\section{References}

Bainton, N.A. 2010. The Lihir destiny: Cultural responses to mining in Melanesia. ANU E Press, Canberra.

Bainton, N.A., Ballard, C., Gillespie, K. and Hall, N. 2011. Stepping stones across the Lihir islands: Developing cultural heritage management in the context of a gold-mining operation. Journal of Cultural Property 18:81-110.

Bayliss-Smith, T.P. 2007. The meaning of ditches: Interpreting the archaeological record using insights from ethnography. In: Denham, T.P, Iriarte, J. and Vrydaghs, L. (eds), Rethinking agriculture: Archaeological and ethnoarchaeological perspectives, pp. 126-148. Left Coast Press, Walnut Creek.

Bedingfield, A. 2009. Archaeological fieldwork at Simbai, Madang Province, Papua New Guinea, May-June 2008. Report prepared for the Papua New Guinea Museum and Art Gallery. Monash University, Clayton.

Bedingfield, A. and Denham, T.P. 2008. Archaeological reconnaissance and community consultation at Simbai, Madang Province, Papua New Guinea, October-November 2007. Report prepared for the Papua New Guinea Museum and Art Gallery. Monash University, Clayton.

Bulmer, A. 1991. Ralph Bulmer - A bibliography. In: Pawley, A. (ed.), Man and a half: Essays in Pacific anthropology and ethnobiology in honour of Ralph Bulmer, pp. 45-54. The Polynesian Society, Auckland.

Bulmer, S. 1977. Between the mountain and the plain: Prehistoric settlement and environment in the Kaironk Valley. In: Winslow, J.H. (ed.), The Melanesian environment, pp. 61-73. ANU Press, Canberra. 
Chisholm, M. 1982. Modern world development: A geographical perspective. Barnes and Noble, New Jersey.

Craig, B. 1996. Samting bilong tumbuna: The collection, documentation and preservation of the material cultural heritage of Papua New Guinea. Unpublished PhD thesis, Flinders University of South Australia.

Denham, T.P. 1996. Understanding the Kalam, understanding ourselves: Reflections on the representation of the Kalam, Bismarck Mountain Range, Papua New Guinea. Unpublished MS thesis, Pennsylvania State University.

Denham, T.P. 1999. Review of 'Kuk heritage: Issues and debates in Papua New Guinea' by Strathern, A. and Stewart, P.J. (eds). Archaeology in Oceania 34:89-90.

Denham, T.P. 2003. Multi-disciplinary investigation of early and mid-Holocene plant exploitation at Kuk Swamp, Wahgi Valley, Papua New Guinea. Unpublished PhD thesis, Australian National University.

Denham, T.P. 2008a. Kuk Swamp. Our Way (PNG Airlines Magazine) 11:38-41.

Denham, T.P. 2008b. A world cradle of agriculture. The UNESCO Courier 6:13-15.

Denham, T.P. 2012. Building institutional and community capacity for World Heritage in Papua New Guinea: The Kuk Early Agricultural Site and beyond. In: Smith, A. (ed.), World Heritage in a Sea of Islands, pp. 98-103. UNESCO, Paris.

Denham, T.P., Haberle, S.G., Lentfer, C., Fullagar, R., Field, J., Therin, M., Porch, N. and Winsborough, B. 2003. Origins of agriculture at Kuk Swamp in the Highlands of New Guinea. Science 301:189-193.

Denham, T.P., Golson, J. and Hughes, P.G. 2004. Reading early agriculture at Kuk (Phases 1-3), Wahgi Valley, Papua New Guinea: the wetland archaeological features. Proceedings of the Prehistoric Society 70:259-98.

Department of Environment and Conservation (DEC) (prepared by Denham, T.P., J. Muke, L. Salas, V. Genorupa and others) 2007. The Kuk Early Agricultural Site: A cultural landscape. World Heritage Nomination (successful), Government of Papua New Guinea, Port Moresby.

Filer, C. and Macintyre, M. 2006. Grassroots and deep holes: Community responses to mining in Melanesia. Contemporary Pacific 18:215-232.

Golson, J. 1977. No room at the top: agricultural intensification in the New Guinea Highlands. In: Allen, J., Golson, J. and Jones, R. (eds), Sunda and Sahul: Prehistoric studies in Southeast Asia, Melanesia and Australia, pp. 601-38. Academic Press, London.

Golson, J. and Swadling, P. 1998. The nomination of Kuk for inclusion on the World Heritage Listing. In: Strathern, A. and Stewart, P.J. (eds), Kuk Heritage: Issues and debates in Papua New Guinea, pp. 1-18. Centre for Pacific Studies, Townsville.

Hettne. B. 1990. Development theory and the three worlds. Longman, Harlow.

Kalam Cultural Museum., Bedingfield, A., Denham, T.P and Swadling, P. 2008. Inventory of artefacts, Kalam Cultural Museum, Simbai [Madang Province, Papua New Guinea]. Monash University, Clayton.

Ketan, J. 1998. An ethnohistory of Kuk. National Research Institute, Port Moresby.

Ketan, J. and Muke, J. 2001. A site management plan for the Kuk World Heritage project in Papua New Guinea. UNESCO (National Commission PNG) and University of PNG, Port Moresby.

Majnep, I.S. and Bulmer, R.N.H. 1977. Birds of my Kalam Country. Auckland University Press, Auckland. 
Majnep, I.S. and Bulmer, R.N.H. 2007. Animals the ancestors hunted. Crawford House, Belair.

Mandui, H. 2006. What is the future of our past? Papua New Guineans and cultural heritage. In: Lilley, I. (ed.), Archaeology in oceania: Australia and the Pacific Islands, pp. 379-382. Blackwell, Oxford.

Mangi, J. 1994. The role of archaeology in nation building. In: Layton, R. (ed.), Conflict in the archaeology of living traditions, pp. 217-227. Routledge, New York.

McNiven, I., David, B., Richards, T., Aplin, K., Asmussen, B., Mialanes, J., Leavesley, M., Faulkner, P. and Ulm, S. 2011. New direction in human colonisation of the Pacific: Lapita settlement of South Coast New Guinea. Australian Archaeology 72:1-6.

Muke, J. 1998. The death (and re-birth) of Kuk: A progress report on the recent developments at the Kuk prehistoric site. In: Strathern, A. and Stewart, P.J. (eds), Kuk Heritage: Issues and debates in Papua New Guinea, pp. 64-86. Centre for Pacific Studies, Townsville.

Muke, J. 2000. Ownership of ideas and things: A case study of the politics of the Kuk prehistoric site. In: Whimp, K. and Busse, M. (eds), Protection of intellectual, biological and cultural property in Papua New Guinea, pp. 96-115. Conservation Melanesia Inc., Canberra.

Muke, J., Denham,T.P. and Genorupa,V. 2007. Nominating and managing a World Heritage Site in the highlands of Papua New Guinea. World Archaeology 39: 324-338.

Richards, P. 1985. Indigenous agricultural revolution. Methuen, London.

Spriggs, M. 2012. Comment. Australian Archaeology 75:15-16.

Strathern, A.J. and Stewart, P.J. (eds). 1998. Kuk Heritage: Issues and debates in Papua New Guinea. Centre for Pacific Studies, Townsville.

Swadling, P. 1973. The human settlement of the Arona Valley, Eastern Highland District, Papua New Guinea. Papua New Guinea Electricity Commission, Port Moresby.

Swadling, P. 1983. How long have people been in the Ok Tedi Impact Region? PNG National Museum Record No. 8. National Museum of Papua New Guinea, Boroko. 